\title{
Correlates of child undernutrition in Yemen
}

\author{
Laetícia R. De Souza*
}

*Correspondence:

laeticia@nepo.unicamp.br; laeticiarsouza@gmail.com University of Campinas / Population Studies Center, Av. Albert Einstein, 1300, Cidade Universitária Zeferino Vaz, Campinas, SP 13083-852, Brazil

\begin{abstract}
Malnutrition is part of a vicious cycle involving biological and social aspects. Some factors are directly associated with malnutrition, such as inadequate dietary intake and incidence of disease, while others (socio-economic in nature) are more distant but no less important. This paper aims at identifying the main correlates of stunting among Yemeni children through a logistic regression model. The results are based on the fourth round of the National Social Protection Monitoring Survey conducted in 2013; which makes this study a baseline assessment of Yemeni child undernutrition before the ongoing civil war. Primarily addressing the most significant factors associated with stunting in Yemen is urgent especially if one considers the country's constant public budget shortages. There are significant differences-in prevalence of child stuntingbetween regions of residence that could be reduced by putting in place local policies aimed at increasing population access to adequate water and good hygiene practices. The Social Welfare Fund (SWF) programme is also important since this benefit is the only source of income for some families. However, if corruption, regional and civil conflict continues, improvements in the SWF will probably not matter. Such interventions, together with policies for changing attitudes towards women's education, would also help to promote proper child feeding practices. Likewise, cultural aspects can explain the aetiology of children's poor growth. Examples include feeding taboos that influence early initiation and duration of breastfeeding. With so many steps to be taken to prevent child malnutrition, it cannot remain an invisible problem.
\end{abstract}

Keywords: Child, Stunting, Yemen

\section{Background}

Malnutrition is part of a vicious cycle involving underlying factors related to biological and social aspects (WHO 1995). Some factors-known as proximal factors-are directly associated with malnutrition, such as inadequate dietary intake and incidences of disease, while others are more distant but no less important. These are socio-economic in nature and are associated with children's nutritional conditions in a number of ways. For instance, poverty can be related to low levels of parental education, poor availability and quality of food, and lack of access to water/sanitation and adequate health care, all of which raise the risks of disease and contribute to poorer nutrient intake levels.

As the relations between child malnutrition and its associated factors are complex, ranging from biological and social to environmental factors, there are several models to explain its determinants. For the purpose of this paper, we have adapted the conceptual

(c) The Author(s) 2017. This article is distributed under the terms of the Creative Commons Attribution 4.0 International License (http://creativecommons.org/licenses/by/4.0/), which permits unrestricted use, distribution, and reproduction in any medium, provided you give appropriate credit to the original author(s) and the source, provide a link to the Creative Commons license, and indicate if changes were made. 
framework constructed by Hien and Hoa (2009). This framework was developed based on Victora et al. (1997), who proposed the use of frameworks and models for analysing the risk factors associated with health outcomes. This conceptual framework allows us to verify how distal factors may operate through intermediate and proximal factors to affect the nutritional status of children (Darteh et al. 2014). The characteristics associated with child malnutrition are then disaggregated into three groups:

1. Distal factors: socio-economic variables such as region of residence, mother's education, access to land, etc;

2. Intermediate factors: environmental and maternal health-related factors; and

3. Proximal factors: incidence of diseases, child's age and sex, etc.

It is worth mentioning that researchers are often affected by the availability of information when empirically examining a phenomenon. With that in mind, our adapted conceptual framework to analyse the associated factors of child nutrition is shown in Fig. 1. According to this model, socio-economic factors may both directly or indirectly influence all the remaining groups of risk factors (with the exception of sex and age). Furthermore, such groups may also include environmental factors (such as household size and infrastructure) and factors related to maternal health (Hein and Hoa 2009). Although our conceptual framework presents a hierarchical structure, we highlight that we take into account the different factors associated with child malnutrition presented in this framework, without considering any potential hierarchy between the factors implicit in it.

This paper aims at assessing child stunting taking into account its associated variables such as socio-economic factors, maternal characteristics, incidence of diseases etc. (as described in Fig. 1). The results are based on the fourth round of the Yemen National Social Protection Monitoring Survey (NSPMS), conducted in 2013.

The importance of this study is twofold: the scarcity of empirical analysis focused on Yemen and the fact that it is based in a survey that took place in a period between two severe crises in the country-i.e., between the 2011 revolution and the beginning of the 2015 civil war. Therefore, the results work as a baseline assessment of the state of Yemeni children before the current ongoing crisis.

\section{Children's nutritional status in Yemen}

Children's nutritional status has been widely used to assess the adequacy of their diet and growth during infancy, as it reflects overall child health and, thus, the overall health of an entire population. The situation of Yemeni children is serious; according to the 2012-2013 NSPMS final report, nearly half of the children below five years old were stunted (42.5\%), and $12.6 \%$ were severely stunted. Wasting affected $9.7 \%$, with $1 \%$ of children aged 6-59 months being severe cases. Furthermore, $32.4 \%$ of children were too thin for their age. Figure 2 illustrates the severity of child malnutrition in Yemen by comparing these statistics to the four levels of the WHO classification for assessing the severity of undernutrition: low, moderate, high and very high malnutrition. As shown in Fig. 2, Yemeni children are suffering from severe undernourishment. Whereas the prevalence 


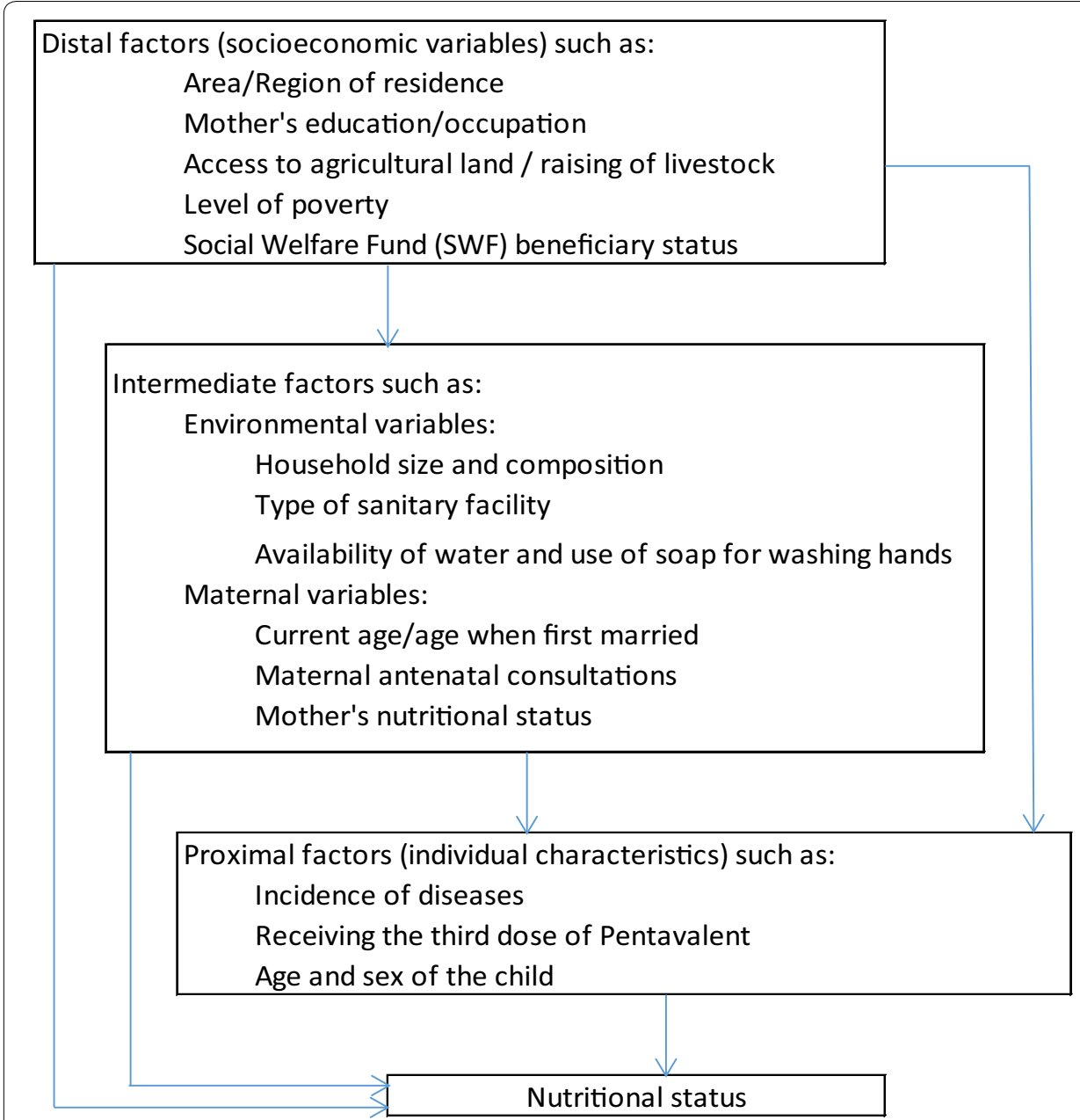

Fig. 1 Conceptual framework of the correlates of children's nutritional status [Source: Adapted from Hein and Hoa (2009)]

of wasting was found to be near the upper bound of the moderate range in 2013, the prevalence of stunting and underweight had reached a high level in the same year.

Child malnutrition in Yemen has decreased over the past decade. Between 1997 and 2003 the percentage of stunted children remained over 50\% (CSO-Yemen and Macro International Inc 1998; and CSO-Yemen et al. 2003), but in 2013 it had fallen to 46.5\% (MOPHP 2015). Nevertheless, Yemeni children are still in a critical situation, especially if we compare the country's statistics with those of a well-nourished population. In a healthy population, only $2.3 \%$ of children would be classified as having low height and/or weight, even if they were 'healthy' individuals with no growth impairment (WHO 1995).

It is worth highlighting the prevalence of stunting among Yemeni children found in previous studies. Both the YNHDS 2013 and the WFP (2012) reports showed that around $46.5 \%$ of Yemeni children under five years old were stunted. The NSPMS data present a lower prevalence of child stunting ( $42.5 \%$ for children aged 6-59 months old) probably because of three main reasons. First, information on child height and/or weight was missing for around $6 \%$ of the children; most of these children had a mother with no 


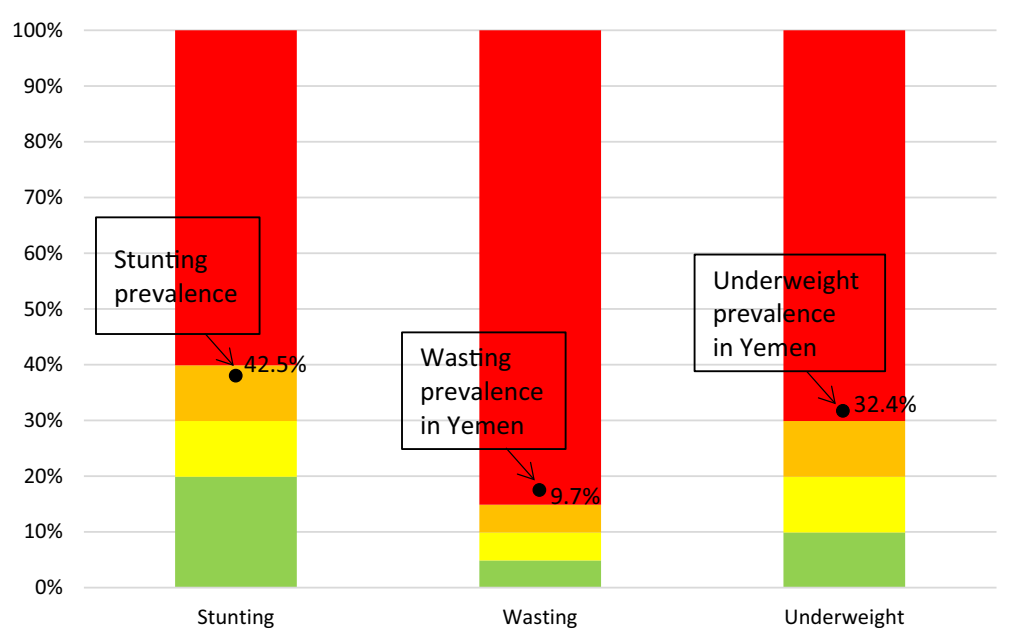

Fig. 2 Malnutrition prevalence in Yemen (in 2013) according to the WHO classification for assessing severity of under-five child malnutrition by expected prevalence ranges. Green low, yellow moderate, orange high, red very high [Source: Classification for assessing severity of malnutrition from WHO (1995); Yemen stunting prevalence from the NSPMS (2012-2013), round 4]

education (53\%) or only basic education (31\%), so they may be over-represented among stunted children. Second, our cross-sectional and longitudinal data cleaning excluded 10\% more children aged 6-59 months old; most of them also had a mother with low education. Finally, as mentioned before, due to security reasons, the Saa'da and Al-Jawf governorates are not included in this analysis which also made our prevalences to diverge.

Therefore, NSPMS estimate may at least be considered as a lower bound of the prevalence of child stunting in Yemen. This is particularly endorsed by the fact that NSPMS 95\% confidence interval actually includes the YNHDS and WFP estimates for child stunting in Yemen (once it varies from 37.9 to $47.3 \%$ ).

Even considering $42.5 \%$ of child stunting as a lower bound, it represents quite a high prevalence. This is an alarming situation, since child stunting is largely irreversible when it is caused by long-term insufficient nutrient intake and frequent infections. The longterm consequences of stunting for adult health and human capital have been emphasized in the literature (Victora et al. 2008).

\section{Children's nutrition in Yemen as compared to Middle East and North Africa region (MENA) and the least developed countries (LDCS)}

While children undernutrition is a major problem in Yemen, it is important to analyse how children's situation in Yemen is inserted in a broader context of undernutrition, taking into account other countries or regions. In this section, we compare Yemeni indicators for stunting and variables related to them considering two groups of countries from which Yemen is part: the Middle East and North Africa region (MENA) and the least developed countries (LDCs). We also show the same indicators for the world as a whole.

Figure 3 shows that the percentage of stunted children in Yemen (42\%) is more than double the percentage of stunted children considering the MENA countries as a whole (18), being even higher than the figure for the LDCs (37). U5MR may be a result of the nutritional well-being of children (and mothers) besides a wide variety of inputs-such 


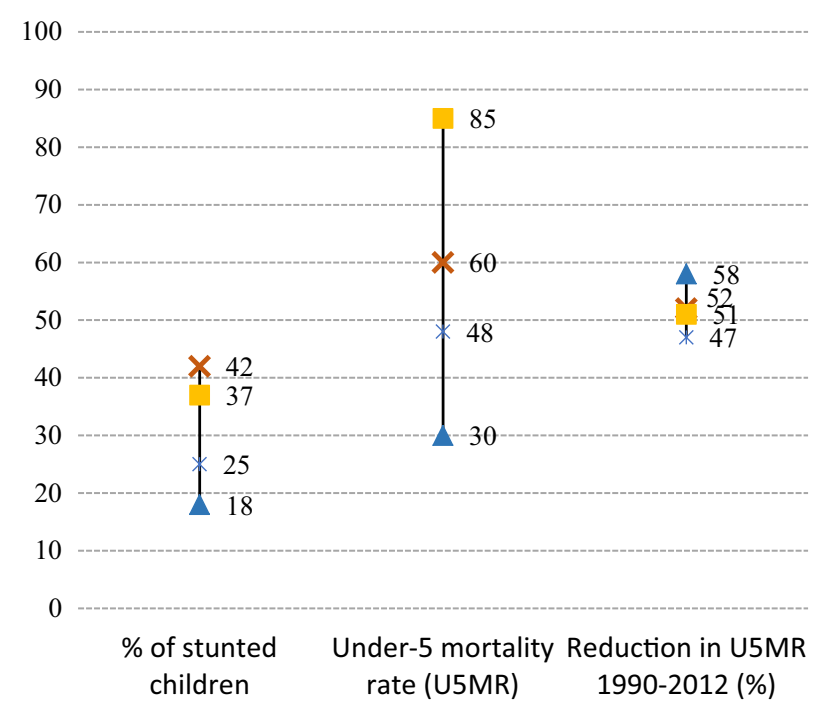

Fig. 3 Stunting and under-five mortality rate (2012) and its percentage reduction (1990-2012) - Yemen, Middle East and North Africa (MENA) and least developed countries (LDCs). Red X mark: Yemen, dark blue triangle: MENA, yellow square LCDs, light blue asterisk World [Source: The State of the World's children in numbers (UNICEF 2014b); Yemen stunting prevalence from the NSPMS (2012-2013), round 4]

as antibiotics treatment for pneumonia, health knowledge of mothers, the level of immunization and oral rehydration therapy use-which may be in turn strongly related to their nutritional status. In Yemen, the probability of a child to die before completing 5 years old is extremely high (60\%), especially if compared to the one referring to the MENA region (30). Additionally, the percentual reduction in U5MR between 1990 and 2012 was lower in Yemen (52\%) when compared to the MENA countries (58). This indicates that progress concerning children's nutrition in Yemen has been too slow since departing from a higher rate should lead to relatively easier reduction in the indicator.

Figure 4 reveals analogous comparisons between Yemen and the MENA countries, the LDCs and the world though focusing on particular characteristics which fit into our conceptual framework of the correlates of children's nutritional status and for which recent estimates are available for the regions selected to be compared. Diarrhea is one of the leading killers of children and is highly related to children undernutrition. Yet treatments are inexpensive and effective (UNICEF 2014b). In spite of these advantages, the use of oral rehydration solutions (ORS) is very low. According to Fig. 4, in Yemen, only $21 \%$ of children under age 5 who had diarrhoea in the 2 weeks preceding the survey, were treated with ORS in 2013. This percentage is still very low in the MENA region (35) and the LDCs (41).

Exclusive breastfeeding in the first 6 months of life reduces the chances of infants dying from diarrhoea, acute respiratory infections and other diseases and has been found to support infants' immune systems (UNICEF 2014b). If children are weaned prematurely, they begin to lose the immunological benefits of breast milk while being exposed to unsafe food, water and unsanitary environments (Seidel 2005). According to IPC-IG and UNICEF (2014a), 41\% of infants under 6 months of age had diarrhea in Yemen. Also, Yemeni children receiving only breast milk had a lower prevalence of diarrhoea (15\% in 2013) when compared to breastfeeding combined with water or sweetened water (24). 


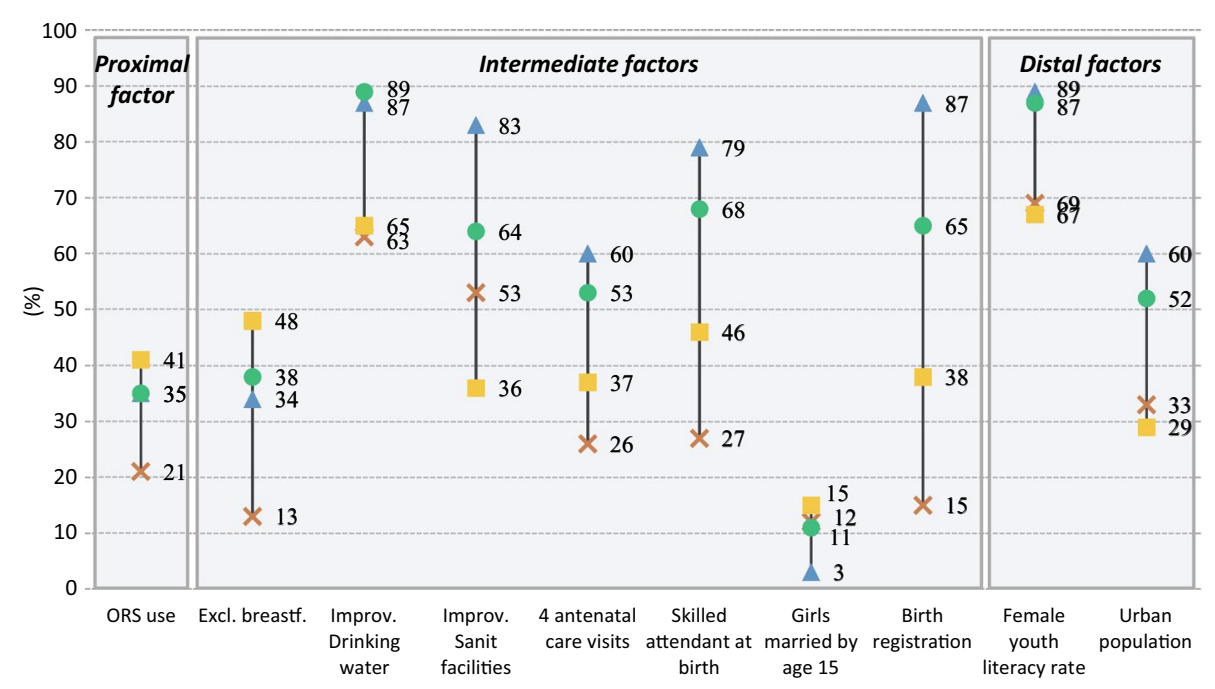

Fig. 4 Prevalence of selected indicators which are correlated with children's nutritional status (2012) Yemen, Middle East and North Africa (MENA) and least developed countries (LDCs). Red X mark: Yemen, dark blue triangle MENA, yellow square LCDs, green circle World [Source: The State of the World's children in numbers (UNICEF 2014b); NSPMS (2012-2013) for Yemen's indicators, round 4]

Despite such a great effect of breastfeeding over the nutrition of younger children, only $13 \%$ of children in Yemen were exclusively breastfed during the first 6 months of life. This may be reflecting more of cultural barriers than any other reason, as this figure reaches $48 \%$ in the LDCs countries. Examples of such barriers include feeding taboos as many women in Yemen believe that their first milk is unclean because of its different colour compared to the milk produced a few days after birth. As a result, some mothers feed their children with a combination of sugar and water, leading children to become increasingly malnourished (UNICEF 2014a).

These child feeding practices become especially risky when the water is not safe. Figure 4 shows that only $63 \%$ of the Yemeni population had access to improved drinking water sources in 2013 while almost $90 \%$ of the population residing in the MENA region had it. If we consider the percentage of population with access to improved sanitation facilities, the Yemeni situation is even worse: virtually half of Yemeni population is able to access it in comparison to $83 \%$ of the MENA countries. The lack of adequate supply of safe drinking water and sanitation contributes to children's deaths and illness. According to UNICEF (2014b), on a daily basis, more than 1400 children die from diarrhoeal diseases because of contaminated drinking water, lack of sanitation and poor hygiene.

The antenatal period presents opportunities for monitoring the pregnancy and providing pregnant women with interventions that improve maternal health as well as the health and survival of infants. This period may inform women and families about possible risks at delivery, ensuring that pregnant women deliver in a health facility or, at least with the assistance of a skilled health care provider (MOPHP and UNICEF 2008; IPC-IG and UNICEF 2014). In Yemen, nearly $1 / 4$ of women aged $15-49$ years had at least 4 antenatal consultations during their last pregnancy and the same fraction had a skilled attendant at the last birth. These figures reach 60 and 79\%, respectively, regarding the MENA region. 
In several parts of the world, parents encourage the marriage of their daughters for both financial and social reasons, jeopardizing girls' rights to health, education and protection. One of the consequences of early marriage is premature and frequent pregnancies, which may contribute to the vicious cycle of malnutrition in Yemen. Adolescent girls, who are usually undernourished, are less likely to finish growing before their first pregnancy. Early pregnancy can siphon away nutrients a girl child needs to develop properly. This leads to maternal malnutrition, which is a major risk factor for maternal mortality and the birth of chronically malnourished children who would reproduce this cycle (IPC-IG and UNICEF 2014). Figure 4 shows that $12 \%$ of young women aged 20-24 years old in Yemen were first married before they had completed 15 years old. Compared to the remaining regions, this percentage is only lower than the one found in the LDCs (15\%). In the MENA region, no more than 3\% of women aged 20-24 years old were married by age of 15 .

Birth registration is the fundamental means to protect children from being deprived of their identity, ensuring their name and nationality. Those not registered may not be able to claim the services and protections due to them on an equal basis with other children. Only 15.2\% of Yemeni children under 5 years of age were registered in 2013.

The IPC-IG and UNICEF (2014) report reveals a very low level of formal education in Yemen. The average number of years of schooling achieved by Yemenis aged 25 and older was 4.2 in 2013, representing less than the full basic education. When disaggregating by gender the situation is even worse for women (2.3 years of schooling) compared to men (6.3). The literacy of 15-24-year-olds is one of the indicators for monitoring educational progress towards the Millennium Development Goals (MDGs). In Yemen, 79\% of population in this age group is literate. Regarding women, this percentage is as low as $69 \%$. The percentage of young women who are literate is seriously low in Yemen especially if we consider: (1) that this is the youngest women age group (concerning older women, we expect an even lower literacy percentage), (2) this is the most basic level of education which refers to the percentage of people who can both read and write, being able to understanding a short simple statement on his/her everyday life and (3) the importance of mothers' education for children's well-being.

Finally, it is important to stress the fact that in many countries rural areas present poorer living conditions in comparison to urban areas. There are several indicators suggesting that this is true in Yemen. In 2013, almost 46\% of the children in rural areas were stunted compared to $27 \%$ in urban areas, the percentage of birth registration among children is as low as $9.7 \%$ in rural areas and $38 \%$ in urban areas and the more than $90 \%$ of urban households have a proper sanitation system, compared to less than $40 \%$ in rural areas (IPC-IG and UNICEF 2014).

As shown in this section, Yemen has many indicators that show the fragility of the country in terms of the situation of their children and, especially, in terms of characteristics related to children's nutrition. More than that, this section revealed that Yemen is in a disadvantageous position in relation to several factors associated with child malnutrition compared to the groups of countries they belong to (the LDCs and MENA region). It is important emphasizing that this study mainly refers to year 2013, which is before the (ongoing) Yemeni Civil War started in 2015, which has probably further worsened this situation. 
As important as contextualizing the high prevalence of stunting in Yemen in comparison with some regions around the world is to analyse how the Government of Yemen (GoY) and partner institutions/organizations are trying to cope with this critical situation. This is our goal in the next section.

\section{Recent initiatives towards children's health and nutrition in Yemen}

A barrier to improving nutrition standards in Yemen is that historically nutrition has not been mainstreamed into health care. There is no explicit reference to child nutrition neither in the National Health Strategy 2010-2025 nor in the Fourth Health Strategic Plan 2011-2015. In the latter, the goal of reducing child mortality is considered a proxy for a reduction on malnutrition (UNICEF 2014a).

According to Black et al. (2013), undernutrition was responsible for almost half of all child deaths in 2011 and it was associated with increased chances of death from infectious diseases such as diarrhea, pneumonia and measles. Stunting is increasingly being accepted as a crucial indicator for children undernutrition and for multiple system failure. Higher prevalence of stunting is linked to maternal nutrition, early pregnancy (which is high in Yemen and associated to early marriage), waterborne diseases and unsafe water. This emphasizes the importance of multi-sectoral responses to the complex challenge of undernutrition.

In Yemen, although most of the barriers to improve nutrition includes factors beyond the control of families (such as intensified conflicts, food price increases and water shortages), there are some factors which are within their control. Households' resource allocation and breastfeeding are examples of decisions made inside families' domain (UNICEF 2014a).

On average, Yemeni households consume qat 3.2 times per week. This is twice their weekly consumption of vegetables and fruits (1.5 times). Concerning breastfeeding, only 13\% of Yemeni children were exclusively breastfed in 2013 (IPC-IG and UNICEF 2014). Both facts highlight the importance of initiatives like the 2010 National Food Security Strategy which defined nutrition-specific priority areas that included improving women's and children's nutrition, improving health services, especially in rural areas and fostering links between nutrition, health and education. It is evident that improved household knowledge and practice are essential to achieving sustainable progress on child malnutrition (UNICEF 2014a).

The Global database on the Implementation of Nutrition Action (GINA) made available by WHO contains information about two policies towards improving nutrition in Yemen that were recently adopted. The National Agriculture Sector Strategy 20122016 is a national policy focused on food security and agriculture sector with a nutrition component. Its goals include increasing rural income, rural employment and food security. GINA also mentions the Cabinet Decree No 91 adopted in April 2013, which defines that the Minister of Public Health and Population should adopt a comprehensive national strategy for nutrition. It also requests that the Ministers of Finance, Planning and International Cooperation and Public Health incorporate the issue of malnutrition into government plans, which includes increasing the budget allocated for nutrition.

In 2012, Yemen also joined the scaling up nutrition (SUN) Movement which established a High Council for Food Security, supported by a multi-sectoral National SUN 
Steering Committee. According to the SUN Annual Progress Report 2015, an operational plan was being prepared for the implementation of the sectoral programs. The Food and Agriculture Organization (FAO), with the European Union support, established a Food Security Information System in 2014 at the Ministry of Planning and International Cooperation (MOPIC). The system was designed to gather information on nutrition-specific and nutrition-sensitive indicators (SUN Movement 2015).

These are some recent initiatives to fight against undernutrition in Yemen. Yet, it is important to emphasize the complexity of tackling supply and quality issues of the Yemeni health sector. Health centers are often understaffed, under-resourced-especially in rural areas-and dependent on humanitarian agencies and charitable organizations for continuing provision of services (UNICEF 2014a).

Due to Yemen's civil unrest, funds that should be invested in accelerating the achievement of the MDGs often need to be overtaken by emergency plans. This was the case of the Fast Track Action Plan (2012-2015) which was not implemented due to the consequences of the 2011 crisis and it was overtaken by the Transition Plan for Stabilization and Development (2012-2014). This change of plans is somehow recurrent in places where civil conflicts are frequent. With the 2015 conflict, the implementation of the National Multi-sectoral Plan has been postponed.

\section{Social issues in Yemen: politics, conflicts, poverty, corruption, and lack of global media coverage}

As can be seen, Yemeni children are facing a prolonged critical situation, which continues to be intensified by political instability, multiple local conflicts and chronic underdevelopment. The MDGs Report produced by the GoY with United Nations Development Programme (UNDP) support concluded that Yemen is off track with respect to achieving the MDGs goals (MOPIC 2010).

After the publication of that report, Yemeni population have been suffering with the consequences of two recent violent conflicts-the uprisings of 2011 and 2015-that has added a huge burden on poor and vulnerable households, which represent the majority of the population in Yemen.

Before discussing both conflicts and its consequences, we briefly outline the history of Yemen's main conflicts since its unification in 1990. With the unification of the Yemen Arab Republic (led by Ali Salim al-Beedh in North Yemen) and the People's Democratic Republic of Yemen (led by Ali Abdullah Saleh in South Yemen) into the Republic of Yemen in 1990, relations between southern and northern Yemenis dramatically deteriorated culminating in the civil war of 1994. The supporters of Saleh won this conflict and the period 1994-2010 was marked by a synergy of negative factors including worsening poverty and limiting of political freedoms. The most democratic regime in the Arabian Peninsula of the early 1990s was losing its pluralism as Yemen's political control was increasingly monopolized by a small group surrounding Saleh. The failure in addressing the main economic problems and improving Yemeni's living conditions resulted in increasing frustration with the regime. As corruption is an historical problem in Yemen, there was a patronage system that distributed some oil income to local leaders, keeping deterioration of relations in a moderate level. However, dissatisfaction emerged 
in several ways. Starting in 2004, there was a series of wars, with the rebels led by the Houthi family (Lackner 2014).

Military operations were conducted in the north of the capital Sa'ada against their supporters without been able to control the Houthi movement, which widespread to southern areas. Along with the south frustration and al-Qa'ida-inspired terrorism, the Houthi conflict is an enduring threat to Yemen's stability (Salmoni et al. 2010).

Saudi Arabia and Yemen share thousands of kilometers of border and similar population sizes which, in addition to the democratic nature of Yemen's regime, makes it to be perceived as a strategic threat by Saudi Arabia. Saudi government has long been supporting various political factions in Yemen and contributed to weaken its government's ability to have effective control over the country (Lackner 2014). Recently, Saudi Arabialed coalition began air strikes against the Houthi rebels. In turn, the Houthis seem to be supported by Iran although the extent of this support and influence remains unclear.

Civilians are the ones who suffer the most with the constant insecurity caused by these sectarian and regional conflicts as they damage key infrastructure making it difficult to Yemenis to have access to clean water, food, fuel and medical supplies. The worsening dissatisfaction prevailing throughout Yemen culminated in the uprisings of 2011. With the steadiness of the demonstrations and with two forces acting in the regime (the ones loyal to Saleh and those supporting the revolutionary movement), it became clear that Saleh regime was no longer sustainable. By the end of 2011, Saleh agreed with a peaceful transition to a new regime and with his departure from power. A Government of National Unity was formed with equal number of representatives from both political forces, as well as representatives of youth and women. This initiative prevented the eminent risk of a civil war in 2011 and brought the hope that its citizens (including youth and women) would participate more actively in the country's politics. The regime emerged from this transition process should give priority to addressing the country's basic needs, focusing on access to water, education, health and employment. However, that opportunity window was lost and the years after the 2011 uprisings were marked by an even more dramatic deterioration in living conditions for most of the Yemenis. Food insecurity and malnutrition indicators have drastically worsened (Lackner 2014).

These conditions got even worse with the 2015 crisis. According to UNICEF (at a Glance: Yemen report), many public health facilities have been damaged or forced to shut down, with more than half of the population having no access to health care by the end of 2015. With agriculture and fishery strongly affected and food imports interrupted by the crisis, families' capacity to feed their children was further reduced.

Yemen's poverty is both cause and consequence of several factors acting in synergy. Political crisis, low educational level, improper infrastructure, extremely high unemployment rates, and on the top of all the aid the country receives is often mismanaged through corruption and the absence of a strategic plan focused on alleviating poverty. Several funding agencies are investing in road construction in Yemen. This is a government priority to ensure people's access to markets, health centers, schools and other facilities and also to ensure security forces access to remote areas when there are conflicts. However, construction is an easy source of corruption through several contractual 
mechanisms. Schools and health centers are constructed on demand of the ones with more power and arms, not being based on the density and number of children in need, for example (Lackner 2014).

Yemen is among the countries with the highest levels of corruption. Along with corruption, Yemen government lacks transparency, accountability, a strong and fair judiciary, decentralization and real practice of the institutionalization of citizen participation in the decision process. These elements of good governance are among the most important factors of change in Yemen since they would bring and maintain harmony in Yemen society. If it were not for corruption and lack of transparency, the aid of donors agencies would have had significant impacts on Yemeni's living conditions (Moghram 2004).

While the population of poor and unemployed grows, officials enriched by abuse of power are severely increasing. This is a vicious cycle that leads to poor service delivery and to a general belief that the only way to get rich is to be corrupt (Uslaner 2017). In this scenario, corruption has been a key galvanizing force for youth recruitment through its consequences such as poverty, unemployment, inequality (Shelley 2014).

In spite of decades marked by deteriorating economic, social and living conditions briefly mentioned in the previous paragraphs, Yemen has not attracted much attention from the global media as other conflict areas. According to Lackner (2014), in the last decade Yemen attracted greater attention from the global media but they were focused on International Jihadism and security issues rather than on Yemen's socioeconomic problems.

While the global community attention is focused on the Syrian refugee crisis, a severe humanitarian and displacement crisis is going unnoticed (Baron 2016; Lopour 2016). Yemen's situation is worse than the one in Syria in terms of both the humanitarian situation and the inability of state control which is giving space to extremist groups. This makes us question the reasons why the global media coverage is so low regarding Yemen's crisis. According to Baron, one of the reasons is related to "the fact that it has long been enmeshed in one conflict or another makes it is easy for people to shrug it off. They recognise that Yemen is at war, but see it as always at war." Also, Europe is worried about conflicts within and near its borders which makes it to be perceived as a controllable far-off conflict. However, the current refugee crisis has shown the potential of large domestic effects that 'far-off' conflicts can cause (Baron 2016). Worldwide discussions on how to mitigate the current refugee crisis did not take place before refugees began crossing European borders. If this repeats with Yemen, the cost in terms of both human and financial issues may be much higher (Lopour 2016).

Hereafter, this paper will focus on understanding the prevalence and correlates of child stunting in Yemen in 2013, always keeping in mind that the situation is probably more severe with the ongoing conflict. The next sections detail the methodology and outcomes of the empirical exercise, respectively. 


\section{Methods}

\section{The survey}

The NSPMS is a longitudinal household survey comprising four rounds of data collection during a period of 12 months-from October 2012 to September 2013 (UNICEF and IPCIG 2014). ${ }^{1}$ This paper is based on the fourth round, with interviews undertaken in July, August and September 2013, as the survey follows a multiple panel rotation scheme. The analysis is based on a sample of 6397 Yemeni households, with the exception of the Saa'da and Al-Jawf governorates, which were not included due to security reasons.

The survey collected data on anthropometric measurements (weight and height/ length) and clinical signs (bilateral oedema) of all children under 5 years, so as to estimate indicators of stunting (child too short for their age), wasting (child too thin for their height/length) and underweight (child too thin for their age).

\section{Methodology}

First we describe our sample. Then we show the results for our model on stunting. As our dependent variable is a dummy variable for stunting in which 1 means the child is stunted and 0 means the child is not stunted, we estimate a logistic model.

In order to classify children as undernourished, we used the reference population from 2006 WHO Child Growth Standards, so that a child whose height-for-age z score $(\mathrm{HAZ})^{2}$ is below -2 standard deviations from the mean is considered stunted.

Children under 6 months old exhibited the highest percentage of implausible measurements in the whole sample; therefore, our analysis encompasses children aged 6-59 months. Among them, there were 527 children with implausible longitudinal growth figures for height, weight or both, and an additional 42 children with implausible $\mathrm{z}$ score values (exceeding three standard deviations from the mean). Missing and implausible values were excluded from the analysis. From the total of 5783 children aged 6-59 months, $16 \%$ (918 children) were excluded relative to the stunting indicator. ${ }^{3}$

Below, we list our independent variables:

\section{Distal factors}

- Mother's schooling;

- Mother's occupation in the last 30 months;

- Sex of the household head;

- Level of poverty (according to the proxy means test (PMT) formula) ${ }^{4}$;

\footnotetext{
1 The NSPMS dataset is freely available and can be downloaded from the webpage dedicated to the project (http:// nspms-yemen.ipc-undp.org/). The NSPMS follows a two-phase stratified sampling design. Therefore, we take into account its complex sample design while estimating any statistics either concerning the descriptive or the multivariate analysis presented in this paper.

2 A z score is the number of standard deviations below or above the median value for the reference population (WHO 2006).

${ }^{3}$ It is important to highlight that screening of implausible child anthropometrics is common in the child malnutrition research field. The International Food Policy Research Institute (IFPRI) report on assessing food security in Yemen (Ecker et al. 2010) is an example of a considerable percentage of children being excluded from the analysis due to implausible and/or missing values. Their cleaned dataset excluded approximately $40 \%$ of the children, especially due to the weak quality of their height measurements. Also, the 2013 National Health and Demographic Survey (YNHDS) preliminary report indicated a high percentage of missing and implausible values: for $9 \%$ of the 16,100 children analysed, weight and/or height were not measured, while for another $4 \%$ the measurements were clearly incorrect and/or the child's age information was incomplete.

${ }^{4}$ For a detailed description of the construction of the level of poverty indicator, please refer to Technical Note n. 6-Note on Some Derived Variables http://nspms-yemen.ipc-undp.org/wp-content/uploads/2015/01/6-Note-on-some-derivedvariables.pdf.
} 
- Area/region of residence;

- Access to agricultural land;

- Raising of livestock;

- Social Welfare Fund (SWF) beneficiary status.

\section{Intermediate factors}

- Food consumption score (FCS) ${ }^{5}$;

- Number of days in which household members ate a source of protein (meat, poultry, fish or eggs);

- Use of bed nets when sleeping;

- Availability of water and use of soap for washing hands;

- Source of water in the household;

- Use of improved toilet facilities;

- Source of fuel for cooking;

- Asset ownership: fridge, TV/radio (proxy for access to information);

- Distance from the nearest health facility;

- Child received the third dose of pentavalent (proxy for health access);

- Household size (number of members) and composition (percentage of children aged less than 60 months);

- Maternal age at time of survey;

- Maternal age at first marriage;

- Number of antenatal consultations (proxy for health access);

- Mother's nutritional status. ${ }^{6}$

\section{Proximal factors}

- Child did not have diarrhoea (last 14 days);

- Child did not have any other health problems (last 14 days);

- Child has received third dose of Pentavalent vaccine;

- Age and sex of the child.

\section{Results and discussion}

\section{Descriptive analysis}

\section{Stunted children: their own, their family and household characteristics}

This section describes the main characteristics of the stunted children. ${ }^{7}$ Figure 5 shows the percentage of children aged 6-59 months who are stunted, according to their mother's education and their household's access to agricultural land (Fig. 3a) and areas/ regions of residence (Fig. 3b).

\footnotetext{
${ }^{5}$ For a detailed description of the construction of the food security consumption score, please refer to Technical Note n. 10-Note on the Food Consumption Score (FCS) Variable http://nspms-yemen.ipc-undp.org/wp-content/ uploads/2015/01/10-Note-on-the-Food-Consumption-Score-FCS-variable.pdf.

${ }^{6}$ Mother's nutritional status, measured by mid-upper arm circumference (MUAC), was the only variable with a high percentage of missing values (13\%), other than the dependent variable on stunting after cleaning (16\%). Although almost half of these children overlapped in terms of missing information concerning the independent and dependent variables, in order not to have our sample reduced, we decided to include children with no information on mother's nutritional status in a separate category; therefore, the mother's nutritional status variable has three categories: mother is severely undernourished (MUAC $<21.3 \mathrm{~cm}$ ); mother is not severely undernourished (MUAC $\geq 21.3 \mathrm{~cm}$ ); and no information on mother's MUAC.

${ }^{7}$ For a general description of all sampled children (regardless of malnutrition statuses), please refer to Table 2 in Appendix.
} 

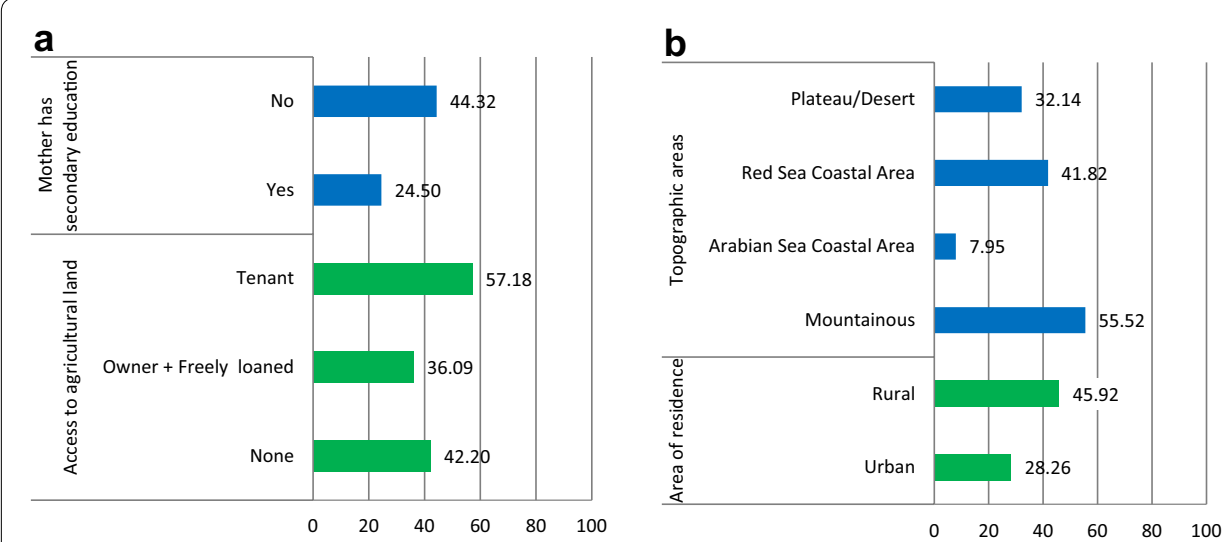

Fig. 5 Percentage of children aged 6-59 months who are stunted, according to selected distal factorsYemen, 2013. a Mother's education and access to agricultural land. b Areas/regions of residence [Source: NSPMS (2012-2013), round 4]

While $36 \%$ of the children who live in a household that owns (or has free use of) agricultural land are stunted, the figure is much higher (57\%) among those who rent land. Differences in maternal education are also striking. Whereas $44 \%$ of the children whose mother does not have a secondary education are stunted, this figure shrinks to $24.5 \%$ for the ones whose mother has had access to better education. The areas of the country with the highest prevalence of stunting are the mountainous ones. More than half (55.5\%) of the children living in such areas are stunted, compared to only $8 \%$ of those living in the Arabian Sea coastal area. Around $28 \%$ of the children who live in urban areas are stunted, compared to $46 \%$ in rural areas.

According to Fig. 6a, the higher is the number of days that household members consumed protein during the week before the survey, the lower the percentage of stunted children is. For instance, $65 \%$ of children living in households whose members had not eaten protein on any day of the previous week are stunted, whereas this percentage falls to less than $30 \%$ among households whose members ate protein every day of the previous week.

Approximately $37.5 \%$ of children living in a household with a radio and/or TV are stunted; this percentage increases to $55 \%$ for households without access to those appliances (Fig. 6b). With regards to fridge ownership, while $26.4 \%$ of children residing in a household with at least one fridge are stunted, this figure rises to around $50 \%$ of those living in a household with no fridge. We also find significant differences when analysing households' access to water and use of soap for hand washing in relation to children's nutritional status: while $37.5 \%$ of children living in households with access to water and better hand-washing practices are stunted. This figure rises to more than $50 \%$ of children living in households with no water and/or no use of soap when washing hands.

Finally, stunted children are over-represented among those living in households with no improved toilet facilities. Whereas almost half of the children who live in households with improved toilet facilities are stunted, this figure decreases to $35.5 \%$ for those living in households with improved sanitation. 


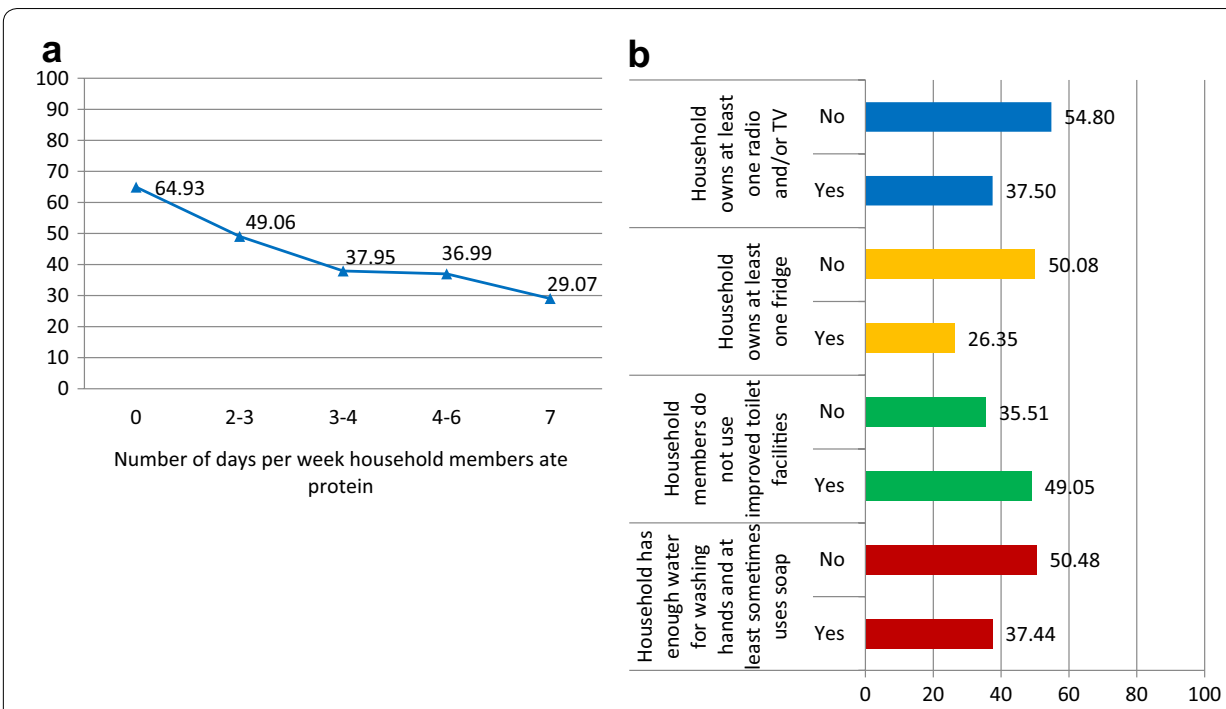

Fig. 6 Percentage of children aged 6-59 months who are stunted, according to selected intermediate factors - Yemen, 2013. a Number of days/week household members ate protein. b Indicators for use of improved toilet facilities, use of water/soap while washing hands and for fridge and radio/TV ownership [Source: NSPMS (2012-2013), round 4]

Figure 7 presents the percentage of children who are stunted by the number of antenatal consultations in the mother's last pregnancy occurring in the last five years (Fig. 7a) and her nutritional status (Fig. 7b). The indicator for mothers who have had at least four antenatal consultations during their last pregnancy (the minimum number recommended by the WHO) works as a proxy for adequate health care access/utilisation. The percentage of children who are stunted among those whose mothers had adequate access to antenatal care in their last pregnancy is considerably lower (31\%) than among children of mothers without access to such care (46\%). Concerning the mother's nutritional status-as measured by their MUAC—-we found that $59 \%$ of children whose

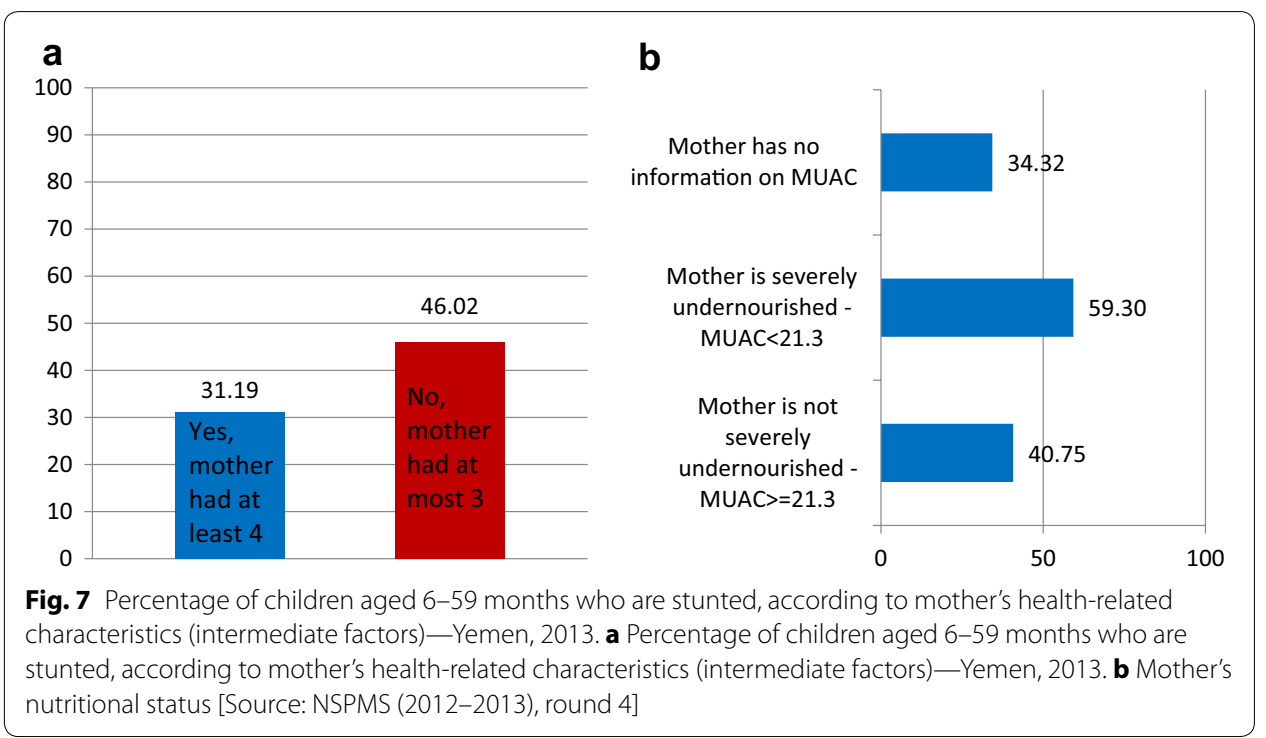


mothers are severely undernourished are stunted, while this figure is just $41 \%$ for those whose mothers are not severely malnourished. Among the children for whose mothers there is no MUAC information, around $34 \%$ are stunted.

This figure is lower than the other categories of the mother's nutritional status, which is unexpected, given that missing information is usually more prevalent among cases in the worst situations. We may speculate that this phenomenon may be related to cultural barriers that prevented the measurements from being taken, which in turn leads us to be cautious when interpreting the outcomes related to this characteristic. However, as the mother's nutritional status is an important predictor of child malnutrition (Krasovec and Anderson 1991; Egal and Oldewage-Theron 2014), it is essential to reinforce the relevance of obtaining high-quality data on women's nutritional status. This is especially an issue when analysing child malnutrition, given that women of reproductive age are among the most vulnerable to malnutrition.

According to age groups (Fig. 8), the highest percentage of stunted children is found in those aged 24-35 months (50.9\%). This is in accordance with the literature on stunting (Martorell and Young 2012), as its peak usually occurs around 24 months of age.

Figure 9 shows the percentage of stunted children by incidence of diarrhoea or other diseases in the 14 days preceding the survey. Around one-third (34\%) of the children who had not had diarrhoea are stunted, compared to over $50 \%$ of those who had had at least one episode of diarrhoea in the 14 days prior to the survey. Regarding the occurrence of diseases other than diarrhoea, 37\% of children who had not had any other diseases were stunted, compared to $52.5 \%$ of those who suffered some other ailment.

\section{Multivariate analysis}

As previously mentioned, a logistic regression was used to further analyse the correlates of stunting among children under 5 years of age in Yemen. Multivariate analysis allows for a better understanding of the association between variables, since it minimises misinterpretations caused by the existence of confounding factors. Our findings indicate that some distal, intermediate and proximal factors are significantly associated with child stunting, even after controlling for quite a lot of confounding factors.

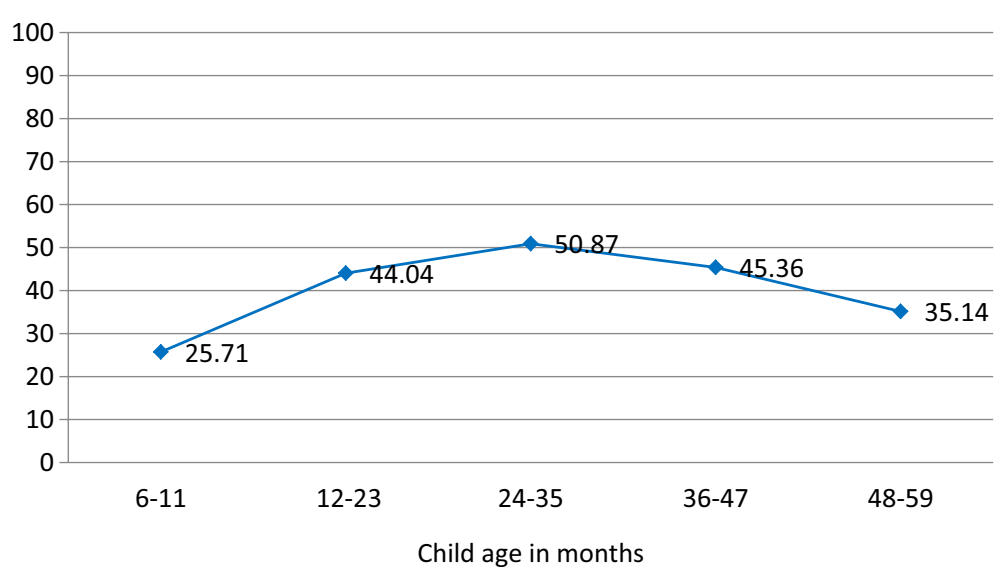

Fig. 8 Percentage of children aged 6-59 months who are stunted, by age groups - Yemen, 2013 [Source: NSPMS (2012-2013), round 4] 


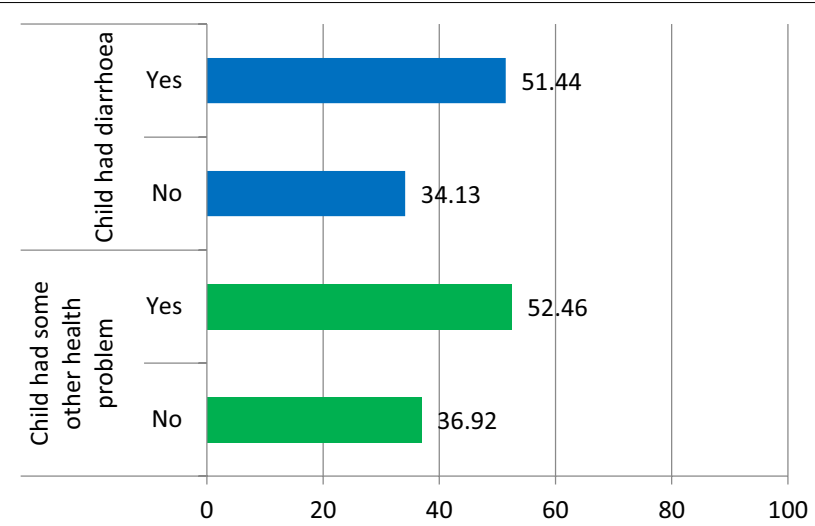

Fig. 9 Percentage of children aged 6-59 months who are stunted, according to the incidence of diarrhoea or other diseases in the previous 14 days - Yemen, 2013 [Source: NSPMS (2012-2013), round 4]

The logistic regression results of the factors associated with child stunting are presented in Table 1 (because of space limitation, we only present the significant odds ratios). There are two important notes to keep in mind while analyzing the results. First, distal factors may affect child malnutrition through other channels. For instance, the level of poverty of a household will be captured by other variables included in the model, such as access to water and sanitation, and assets ownership. Therefore, it would be incorrect to think that the level of poverty has little to no impact on children's nutritional status after adjustment for confounding factors, since the overall effect of this variable will be underestimated due to the presence of mediating factors.

Secondly, it is important to be aware that the odds ratios found in our main model should not be interpreted as numbers per se, but as an approximate association between each specific child characteristic and their probability of being stunted given the model's specification. This is so because as we have a high percentage of missing information on stunting ( $16 \%$ of all children aged 6-59 months), we imputed the missing values based on different rules in order to verify whether the exclusion of these children from our analysis introduced bias to our estimates. Thus, we ran several models on stunting, among which the only differences were the rules under which the missing values in stunting were imputed; this way, we included as many children as possible in the models (keeping those who had information for all the remaining variables being studied).

Table 1 shows both our main model (column in grey) and examples of the 'imputed models' (remaining columns) detailing how the missing data were imputed in each case. It should be noted that including all children aged 6-59 months-by imputing their stunting status whenever it was missing-does not produce substantive changes in the results presented in the main model. The direction of the odds ratios (in terms of showing negative or positive association with the dependent variable) remains identical and although the magnitude and/or significance of the odds indicated some variation, our main results remain unchanged. Finally, when analysing the 'imputed models', it is possible to identify the boundaries between which the odds ratio of each independent variable may be found. This is the reason why the magnitude of the odds of the distal, intermediate and proximal factors found in our main model should be interpreted as an 


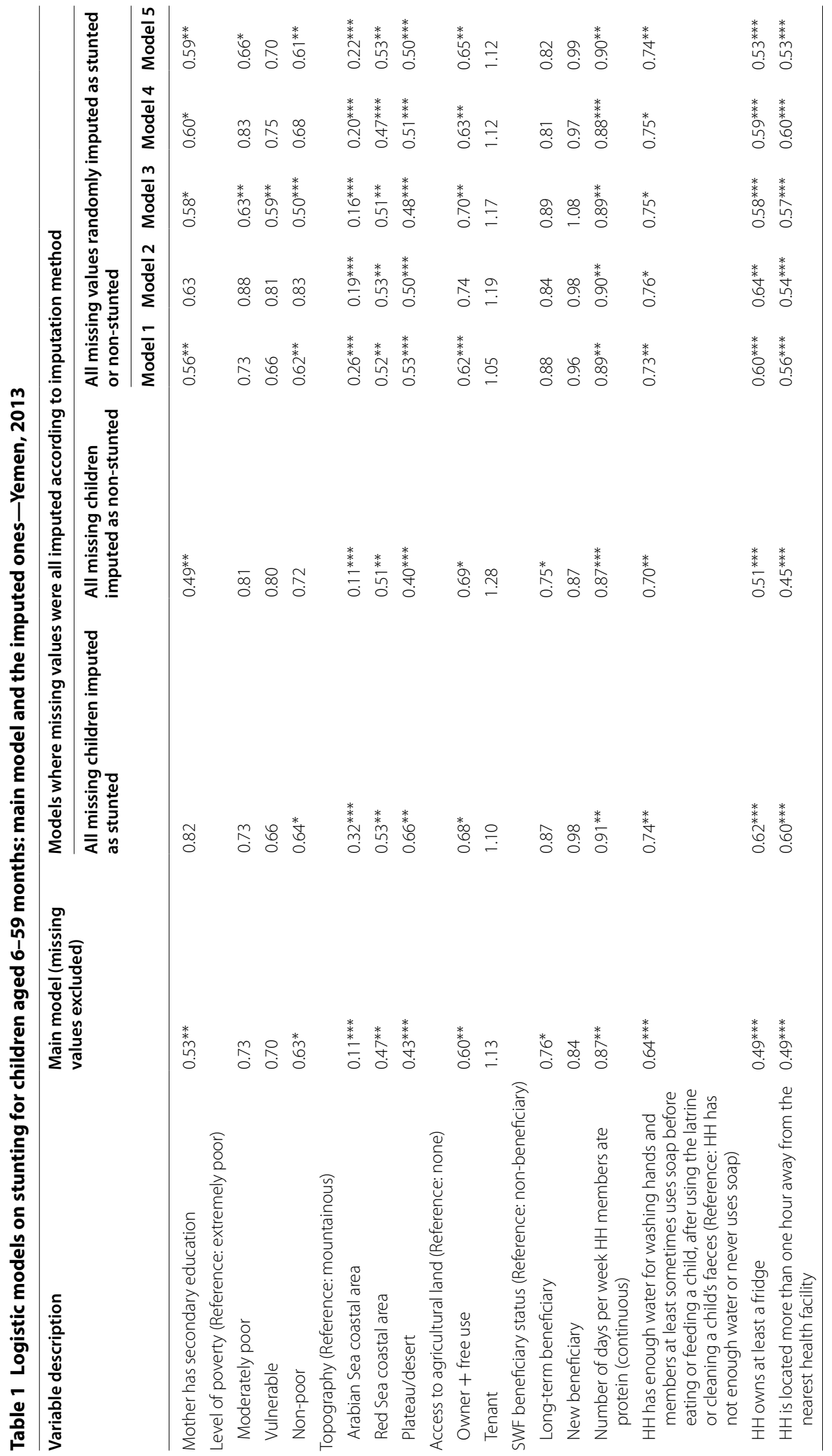




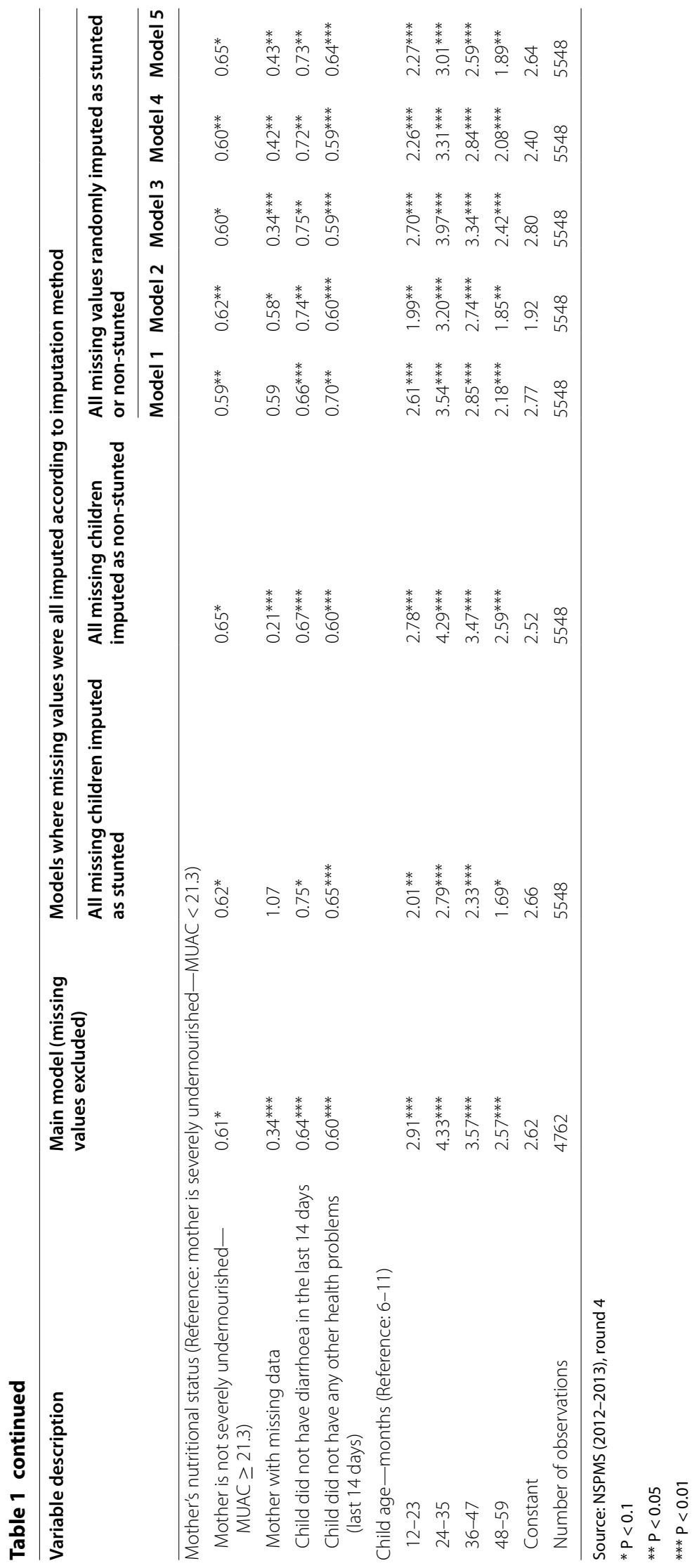


approximate association with the probability of stunting. With that in mind, we dedicate the remainder of this section to the analysis of the results of our main model itself.

\section{Distal factors}

Mother's educational attainment plays a substantial role in stunting among Yemeni children under the age of 5 . Children whose mothers have secondary education are less likely to be stunted than other children. We have tried some different categorisations such as considering four educational attainment categories or even a continuous variable. The results showed that having a mother with secondary education makes all the difference, reducing the likelihood of being stunted by $47 \%$.

Level of poverty is a measure originating in the PMT formula. Simply put, it is a score that combines information on the household's and the head of the household's characteristics, asset ownership, social categories (partially disabled or severely ill, fully disabled or severely ill, elderly, orphans) and economic categories (unemployed, women without a breadwinner). The level of poverty variable has four categories: extremely poor, moderately poor, vulnerable and non-poor. In fact, we found that being non-poor is marginally negatively associated with the probability of being stunted (OR 0.63, $\mathrm{p}<0.10$ ).

Access to agricultural land, although one of the dimensions used to estimate the PMT score (and subsequently used to generate the level of poverty variable), is also included in the model to ensure that information on access to land is taken into account, regardless of PMT score. According to our model, having free access to land is significantly associated with a reduction in the probability of being stunted (OR $0.60, p<0.05$ ).

Topography was significantly related to stunting. It disaggregates the areas of residence into mountainous area, the Arabian Sea coastal area, the Red Sea coastal area and the plateau/desert area. The highest levels of child stunting are found in the mountainous area. For instance, living in the Arabian Sea coastal area is associated with a considerable reduction in the likelihood of being stunted (OR 0.11, p $<0.01$ ). Differences in child stunting among regions could be due not only to natural conditions (such as climate and soil) but also to differences in values, beliefs and cultures between the regions. Regarding areas of residence (whether rural or urban), there was no statistical association with child stunting. This outcome would seem counterintuitive, since there were significantly fewer urban children among those who are stunted than their non-stunted counterparts. Furthermore, other studies have found that food insecurity is far more widespread in rural areas than urban areas (Ecker et al. 2010). The lack of statistical significance concerning this variable indicates a strong correlation with other predictors. In fact, when individually analysing the correlation between each of the covariates and the dummy variable on urban residence, we found that the inequality between urban and rural areas is mainly explained by household access to agricultural land and raising livestock.

SWF beneficiary status proved to be marginally significant towards explaining stunting. Living in a household where there is at least one long-term beneficiary of the SWF is correlated with a reduction in the probability of being stunted (OR $0.76, \mathrm{p}<0.10)$. 


\section{Intermediate factors}

Protein intake is closely related to child stunting. The more often the children ate protein in the previous week, compared to not eating any (in terms of number of days), the lower their likelihood of being stunted (OR 0.87, $\mathrm{p}<0.05$ ).

Availability of water combined with soap use while washing hands demonstrated a significant relationship with child stunting. Having enough water for washing hands and using soap at least sometimes before eating, before feeding a child, after using the latrine and after cleaning a child's faeces is associated with a decrease of $36 \%$ in the probability of a child being stunted.

Ownership of a fridge is also a component of the PMT formula; it was included in the model to identify households which own one, regardless of their PMT score. Owning a fridge is correlated with a $51 \%$ reduction in the probability of a household containing a stunted child.

Living in a household located far from a health facility (more than $1 \mathrm{~h}$ away from the nearest one) is strongly associated with a lower chance of a child being stunted (OR 0.49, $\mathrm{p}<0.01$ ). This was the only unexpected result of the model. We would have expected that living far from a health facility would mean poorer access to health care, therefore being correlated to a higher chance of a child being stunted. One reason for this unexpected outcome may be that households located at least $1 \mathrm{~h}$ away from the nearest health facility in Yemen are actually the wealthiest. Nevertheless, further investigation is needed regarding this result.

Having a mother who is not severely undernourished is marginally associated with a lower chance of a child being stunted than among children whose mothers were severely malnourished (OR 0.61, $\mathrm{p}<0.10$ ). Furthermore, children whose mothers had no MUAC information also showed a lower likelihood of being stunted than those with severely undernourished mothers (OR 0.34, $\mathrm{p}<0.01$ ). This result reinforces the relevance of accurately measuring the mother's nutritional status (either through MUAC, waist circumference, body mass index or any other characteristic that may work as a proxy for the mother's nutritional status), which could be helpful in understanding the factors associated with child malnutrition.

\section{Proximal factors}

The age of the child was significantly associated with its likelihood of being stunted. Children aged 24-35 months showed the highest probability of being stunted; they were 4.3 times more likely to be stunted than those aged 6-11 months. This evidence supports the literature about the age when stunting reaches its peak (around 24 months).

Incidence of diarrhoea and incidence of other health problems in the previous 14 days are both strong predictors of child stunting. Not having diarrhoea is associated with a reduction of $36 \%$ in the likelihood of being stunted, and not having any diseases other than diarrhoea is correlated to a reduction of $40 \%$.

\section{Robustness check}

As a final robustness check, we run models including indicators for adequate breastfeeding and minimum dietary diversity; both information are available in the Yemen NSPMS dataset, although only for children aged less than 24 months. This would allow us to 
verify whether the inclusion of these variables would change the magnitude and significance of our main predictors of stunting. Besides a not desirable reduction in our sample size, the other reason for not including these variables in our main model is that they are not available for children aged over 23 months. As the prevalence of stunting reaches its peak at 24 months of age, a model including only children aged 6-23 months would not adequately contribute to a better understanding of the correlates of child stunting.

We first estimated a model for children aged 6-23 months where we only included the variables specified in our main model. Then we included: (1) an indicator on the child having the minimum dietary diversity in the previous $24 \mathrm{~h}$; and (2) an indicator on the child being breastfed from the first hour of their birth. Both variables were significant (at $5 \%$ ) and indicated that they were associated with a strong reduction in the likelihood of a child being stunted. Nonetheless, the inclusion of both indicators on child feeding in the model has not substantially changed the odds ratios or the statistical significance of the other relevant variables. Thus these models allow us to conclude that our main findings would remain after controlling for adequate child feeding: mother's nutrition and education, access to land, living in a household where there is at least one long-term SWF beneficiary (marginally significant), living in a non-poor household (marginally significant), eating protein more often, having good hygiene practices-such as washing hands with water and soap, owning a refrigerator and not having a disease-remain strongly associated with a lower likelihood of child stunting in Yemen. It is worth mentioning though that when adding the 'minimum dietary diversity' and 'timely start of breastfeeding' variables to the model, the significance of the mother's nutritional status is reduced.

This evidence suggests that adequate feeding may compensate for the deleterious effects that the mother's undernourishment may have on her child's nutrition, as the significance of the odds ratio for the 'mother's nutritional status' variable tends to diminish after including the 'adequate feeding' and 'timely breastfeeding' variables.

\section{Conclusion}

Yemen is marked by continued health system problems, low education, poverty and conflict, and poor public budget. Several factors contribute to the spread of communicable and preventable disease outbreaks such as the disruption of social services including water, sanitation and electricity and high food and fuel prices. Besides that, health centers are often understaffed and under-resourced, especially in rural areas (UNICEF 2014a). The complexity of tackling supply and quality issues concerning the health sector in such a context emphasizes the need of well targeted policies. This study indicates which factors should be the focus of the Yemeni Social Protection System in order to reduce child undernutrition.

Yemen presents a quite high prevalence of child stunting (42.5\% in 2013). This is an alarming situation, since child stunting is: (1) largely irreversible if it is caused by longterm insufficient nutrient intake and frequent infections and (2) there are serious longterm consequences of stunting for adult health and human capital (Victora et al. 2008). Moreover, it is important to keep in mind that the information analysed in this study mainly refers to year 2013, which is on one hand after the Yemen's 2011 crisis (which had major negative economic and social impacts and exacerbated the existing fragile situation) and on the other hand it is before the (ongoing) Yemeni Civil War that started by 
the beginning of 2015. This means that the situation in Yemen is probably worse than the one reported in this paper.

Primarily addressing the most significant factors associated with stunting in Yemen is urgent especially if one considers the context of constant public budget shortage suffered by the country. There are significant differences in the prevalence of child stunting between regions of residence, with the highest levels of child stunting being found in the mountainous areas. These differences could be reduced by putting in place local policies aimed at increasing population access to adequate water and good hygiene practices in order to promote adequate food intake-which need to apply not only to children but also to their mothers (especially while nursing).

It is important to mention the relevance of the public unconditional cash transfer programme administered by the Social Welfare Fund (SWF). IPC-IG and UNICEF (2014) and UNICEF (2014a) showed that the benefit is the only source of income for some families. Without the SWF, these families would not be able to buy even the most basic food items. However, the payment schedule of the benefits was not followed, with the transfers often made in a lump sum rather than quarterly. Irregular payment cycle seems to not allow households to smooth their consumption over the year, which in turn reduces the effectiveness of the cash transfers in helping families to cope with economic crisis. This may be one of the reasons why we found the SWF to be only marginally significant towards explaining stunting. Exploring the possibility of increasing transfer frequency or making the payment schedule more flexible would be strongly recommended.

Such interventions, together with policies aiming at changing attitudes towards women's education, would also help to promote proper child feeding practices with possible consequences for reducing the incidence of diarrhoea, another important correlate of child stunting.

Cultural aspects closely related to socio-economic factors can help to explain the aetiology of children's poor growth as well. Examples include feeding taboos that can influence early initiation and duration of breastfeeding, and general childcare practices (WHO 1995). According to UNICEF (2014a), many women in Yemen believe that the first milk produced is unclean because of its different colour compared to the milk produced a few days after birth. As a result, some mothers feed their children with a combination of sugar and water, leading children to become increasingly malnourished. Also, a lack of confidence in the ability to breastfeed is causing Yemeni women to turn away from it. This insecurity is furthered by the marketing campaigns of companies that produce infant formula. Women believe that, ideally, feeding their children should be exactly like in the adverts, but they do not realise that their children's formula is usually mixed with impure water and placed in unsterilised bottles, which often causes the child to become ill. In this context, there is an urgent need to improving the newborn mother's knowledge and practice of the benefits of early and exclusive breastfeeding and to regulate inappropriate sales promotion of infant foods which can replace breast milk (UNICEF 2014a).

Finally, it is important to stress that the spillover and generational impacts of disease, malnutrition and displacement will take decades to overcome as thousands of Yemeni children are growing up malnourished, without education and in an environment where the few jobs available involve handling weapons against others (Baron 2016). 
International attention and aid funding is extremely needed, being critical to anticipate a Yemeni refugee crisis. Yet, Yemen's crisis has been mostly under-reported and eclipsed by other conflicts such as Syria. Billions have been spent as a reaction to the Syrian refugee crisis but unless donors start addressing the severity of the situation in Yemen, the cost in terms of both human and financial issues may be much higher (Lopour 2016). Also, international attention is urgently needed concerning the high levels of corruption in the country as besides reducing foreign investments, it may ruin the effects of Yemen's social policies. One can speculate, for instance, that if it had not been for corruption, the impact of the SWF on children's undernourishment identified in this study might have been significantly higher.

Malnutrition crisis in Yemen is a growing problem that has been neglected and forgotten. With so many steps to be taken to prevent child malnutrition, it cannot remain an invisible problem (Eshaq et al. 2017).

\section{Acronyms}

CSO: Central Statistical Organization; IFPRI: International Food Policy Research Institute; IPC-IG: International Policy Centre for Inclusive Growth; MOPHP: Ministry of Public Health and Population; MOPIC: Ministry of Planning and International Cooperation; PAHO: Pan American Health Organization; PAPFAM: Arab Program for Family Health; UNICEF: United Nations International Children's Emergency Fund; WFP: World Food Programme; WHO: World Health Organization; YNHDS: Yemen National Health and Demographic Survey.

Competing interests

The author declares that there are no competing interests.

\section{Appendix}

See Table 2.

Table 2 Descriptive statistics, all children aged 6-59 months-Yemen, 2013

\begin{tabular}{|c|c|c|c|}
\hline \multirow[t]{3}{*}{ Variables description } & \multicolumn{3}{|c|}{ All children } \\
\hline & \multirow[t]{2}{*}{ Value } & \multicolumn{2}{|c|}{ Confidence interval } \\
\hline & & Lower bound & Upper bound \\
\hline \multicolumn{4}{|l|}{ Prevalence of stunting (dependent variable) } \\
\hline Percentage of stunted children & 42.60 & 37.92 & 47.27 \\
\hline Percentage of severely stunted children & 12.61 & 9.69 & 15.53 \\
\hline \multicolumn{4}{|l|}{ Distal factors (socioeconomic characteristics) } \\
\hline Mother has secondary education & 8.70 & 6.35 & 11.04 \\
\hline Mother had no occupation in the last 30 days & 44.11 & 38.95 & 49.27 \\
\hline Female household head & 3.60 & 2.51 & 4.69 \\
\hline \multicolumn{4}{|l|}{ Level of poverty (Reference: extreme poor) } \\
\hline Poor & 14.77 & 11.02 & 18.51 \\
\hline Moderate poor & 27.55 & 23.15 & 31.95 \\
\hline Vulnerable & 18.68 & 15.14 & 22.21 \\
\hline Non-poor & 39.00 & 33.99 & 44.02 \\
\hline Urban area of residence & 18.85 & 14.13 & 23.58 \\
\hline \multicolumn{4}{|l|}{ Topography (Reference: mountainous) } \\
\hline Mountainous & 41.81 & 35.31 & 48.31 \\
\hline Arabian Sea coastal area & 5.02 & 3.32 & 6.73 \\
\hline Red Sea coastal area & 19.57 & 13.36 & 25.79 \\
\hline Plateau/Desert & 33.59 & 28.08 & 39.10 \\
\hline
\end{tabular}


Table 2 continued

\begin{tabular}{|c|c|c|c|}
\hline \multirow[t]{3}{*}{ Variables description } & \multicolumn{3}{|c|}{ All children } \\
\hline & \multirow[t]{2}{*}{ Value } & \multicolumn{2}{|c|}{ Confidence interval } \\
\hline & & Lower bound & Upper bound \\
\hline \multicolumn{4}{|l|}{ Access to agricultural land (Reference: none) } \\
\hline None & 53.43 & 48.59 & 58.27 \\
\hline Owner + freely loaned & 31.21 & 26.59 & 35.83 \\
\hline Tenant & 15.36 & 12.23 & 18.49 \\
\hline Household raise some livestock & 63.88 & 58.71 & 69.05 \\
\hline \multicolumn{4}{|l|}{ SWF beneficiary status (Reference: non-beneficiary) } \\
\hline Non-beneficiary & 74.11 & 70.84 & 77.38 \\
\hline Old-beneficiary & 15.99 & 13.74 & 18.24 \\
\hline New-beneficiary & 9.90 & 7.77 & 12.04 \\
\hline \multicolumn{4}{|l|}{ Intermediate factors (environmental and maternal characteristics) } \\
\hline \multicolumn{4}{|l|}{ Environmental characteristics } \\
\hline Food consumption score (continuous) & 57.00 & 54.87 & 59.13 \\
\hline $\begin{array}{l}\text { Number of days per week household members ate protein (continu- } \\
\text { ous) }\end{array}$ & 2.92 & 2.63 & 3.20 \\
\hline Household members use bed net when sleeping & 21.77 & 17.08 & 26.46 \\
\hline $\begin{array}{l}\text { Household has enough water for washing hands and members at } \\
\text { least sometimes uses soap before eating or feeding a child, after } \\
\text { using the latrine or cleaning a child's faeces (Reference: Household } \\
\text { has not enough water or never uses soap) }\end{array}$ & 60.50 & 55.61 & 65.38 \\
\hline $\begin{array}{l}\text { Main source of water in the household is piped water (both inside } \\
\text { the dwelling and inside the compound) }\end{array}$ & 34.34 & 28.58 & 40.10 \\
\hline $\begin{array}{l}\text { Household members do not use improved toilet facilities: Pit latrine } \\
\text { with slab as hole cover Pit latrine without slab/open hole; bucket; } \\
\text { hanging toilet or latrine discharging to the open; no facilities/ } \\
\text { bush/field/in the open; flush toilet to outside the house or to } \\
\text { unknown place (Reference: improved health facilities) }\end{array}$ & 55.60 & 50.15 & 61.05 \\
\hline $\begin{array}{l}\text { Main source of fuel for cooking is gas or electricity-electricity is a } \\
\text { residual category }\end{array}$ & 55.11 & 49.18 & 61.05 \\
\hline Household own at least one fridge & 31.53 & 26.88 & 36.18 \\
\hline $\begin{array}{l}\text { Household own at least one radio and/or TV (Reference: does not } \\
\text { own neither one) }\end{array}$ & 70.54 & 65.84 & 75.23 \\
\hline $\begin{array}{l}\text { Household is located more than one hour from the nearest health } \\
\text { facility }\end{array}$ & 25.44 & 19.84 & 31.05 \\
\hline \multicolumn{4}{|l|}{ Household size in terms of number of members (Reference: 1-4) } \\
\hline $1-4$ & 8.15 & 4.88 & 11.42 \\
\hline $5-8$ & 45.34 & 40.68 & 50.00 \\
\hline $9+$ & 46.51 & 42.73 & 50.29 \\
\hline $\begin{array}{l}\text { Percentage of the household members aged less than } 60 \text { months } \\
\text { (continuous) }\end{array}$ & 26.69 & 25.52 & 27.86 \\
\hline \multicolumn{4}{|l|}{ Maternal characteristics } \\
\hline \multicolumn{4}{|l|}{ Maternal age at time of survey (Reference: 15-24) } \\
\hline $15-24$ & 21.68 & 17.96 & 25.40 \\
\hline $25-34$ & 48.81 & 44.19 & 53.42 \\
\hline $35-44$ & 22.32 & 18.58 & 26.07 \\
\hline $45+$ & 7.19 & 4.34 & 10.05 \\
\hline \multicolumn{4}{|l|}{ Maternal age at first marriage (Reference: 10-14) } \\
\hline $10-14$ & 7.95 & 6.10 & 9.79 \\
\hline $15-19$ & 60.37 & 55.07 & 65.67 \\
\hline $20-24$ & 21.17 & 17.37 & 24.97 \\
\hline $25+$ & 10.51 & 6.27 & 14.76 \\
\hline
\end{tabular}


Table 2 continued

\begin{tabular}{llll}
\hline Variables description & \multicolumn{3}{l}{ All children } \\
\cline { 2 - 4 } & Value & \multicolumn{2}{l}{ Confidence interval } \\
\cline { 2 - 4 } & & Lower bound & Upper bound \\
\hline Mother had at least 4 antenatal consultations in her last pregnancy & 23.08 & 17.98 & 28.18 \\
occurred in the last 5 years & & & \\
Mother's nutritional status (Reference: MUAC < 21.3) & & & 86.50 \\
Mother is not severely undernourished-MUAC $\geq 21.3$ & 82.63 & 78.76 & 14.95 \\
Mother is severely undernourished-MUAC <21.3 & 11.86 & 8.77 & 7.74 \\
Mother has no information on MUAC & 5.51 & 3.28 & \\
Proximal factors (individual characteristics) & & & 11.10 \\
Child age in months (Reference: 6-11) & & & 26.90 \\
6-11 & 9.31 & 7.53 & 26.74 \\
12-23 & 23.69 & 20.49 & 26.30 \\
24-35 & 24.16 & 21.58 & 21.69 \\
36-47 & 23.70 & 21.10 & 55.67 \\
48-59 & 19.13 & 16.58 & 71.27 \\
Child is a boy & 51.52 & 47.37 & 55.32 \\
Child has received third dose of pentavalent vaccine & 66.55 & 61.84 & 67.99 \\
Child didn't have diarrhoea in the last 14 days & 51.09 & 46.85 & \\
Child didn't have any other health problem in the last 14 days & 63.50 & 59.01 & \\
Number of observations & 4762 & & \\
\hline
\end{tabular}

Source: NSPMS (2012-2013), round 4

Received: 12 December 2016 Accepted: 24 March 2017

Published online: 03 April 2017

\section{References}

Baron, A. 2016. Yemen's forgotten war: how Europe can lay the foundations for peace. European Council for Foreign Relations. Policy Memo. December, 2016.

Black, E.R., C. Victoria, S. Walker, Z. Bhutta, P. Christian, M. De Onis, M. Ezzati, S. Grantham-McGregor, J. Katz, R. Martorell, and R. Uauy. 2013. Maternal and child undernutrition and overweight in low-income and middle-income countries. Lancet 382: 427-451.

CSO-Yemen, and Macro International Inc. 1998. Yemen Demographic and Maternal and Child Health Survey. Calverton: Macro International Inc.

CSO-Yemen, League of Arab States, MOPHP and PAPFAM, League of Arab States, MOPHP, and PAPFAM. 2003. Yemen Family Health Survey. Sana'a: CSO-Yemen.

Darteh, E.K., E. Acquah, and A. Kumi-Kyereme. 2014. Correlates of stunting among children in Ghana. BMC Public Health 14: 504.

Ecker, O., C. Breisinger, C. McCool, X. Diao, J. Funes, L. You, and B. Yu. 2010. Assessing food security in Yemen: an innovative integrated, cross-sector, and multilevel approach. Washington: IFPRI.

Egal, A.A., and W.H. Oldewage-Theron. 2014. Maternal waist circumference as a prediction of children's stunted status. South African Journal of Clinical Nutrition 27 (3): 108-109.

Eshaq, A.M., et al. 2017. Malnutrition in Yemen: an invisible crisis. The Lancet 389 (10064): 31-32.

Hein, N.N., and N.N. Hoa. 2009. Nutritional status and determinants of malnutrition in children under three years of age in Nghean, Vietnam. Pakistan Journal of Nutrition 8 (7): 958-996.

IPC-IG, and UNICEF. 2014. Yemen National Social Protection Monitoring Survey (NSPMS): 2012-2013. Final Report. Brasília: IPC-IG.

Krasovec, K., and M.A. Anderson. 1991. Maternal nutrition and pregnancy outcomes: anthropometric assessment, 529. Washington: $\mathrm{PAHO}$.

Lackner, H. 2014. Introduction. In Why Yemen matters: a society in transition, ed. H. Lackner, 1-26. London: Saqi Books. Lopour, J. 2016. Spotlight on Yemen's forgotten war and humanitarian disaster. Preventing the next syrian refugee crisis. CIGI Paper Series No. 97 
Martorell, R., and M.F. Young. 2012. Patterns of stunting and wasting: potential explanatory factors. Advances in Nutrition 3: 227-233.

Moghram, M.A. 2004. Political culture of corruption and state of corruption in Yemen. Sana'a: Sana'a University.

MOPIC. 2010. The second national millennium development goals report. Sana'a: MOPIC.

MOPHP, and UNICEF. 2008. Yemen Multiple Indicator Cluster Survey 2006, Final Report. New York: UNICEF.

MOPHP, CSO, PAPFAM, MEASURE DHS, and ICF International. 2015. Yemen National Health and Demographic Survey 2013. Rockville: MOPHP, CSO, PAPFAM, and ICF International.

Salmoni, B., L. Bryce, and W. Madeleine. 2010. Regime and periphery in Northern Yemen: the Huthi Phenomenon. Arlington: RAND National Defense Research Institute.

Shelley, L.I. 2014. Corruption and youth's recruitment into violent extremism. In Countering radicalization and violent extremism among youth to prevent terrorism, ed. Lombardi M, et al. Volume 118 of NATO Science for Peace and Security Series-E: Human and Societal Dynamics. Amsterdam: IOS Press.

Seidel, R. 2005. Behavior change perspectives and communication guidelines on six child survival interventions. Washington: Academy for Educational Development, Global Health, Population \& Nutrition Programs, and Baltimore, Johns Hopkins University, Center for Communications Programs.

SUN Movement. 2015. SUN Movement Annual Progress Report 2015.

UNICEF. 2014a. Situation analysis of children in Yemen. UNICEF: Sana'a.

UNICEF. 2014b. The State of World's children in numbers. Every child counts: revealing disparities, advancing children's rights. UNICEF: Sana'a.

UNICEF, and IPC-IG. 2014. '2012-2013 Yemen national social protection monitoring survey: Version 1' (Machine-readable database). Brasília: IPC-IG.

Uslaner, E.M. 2017. Introduction. In Handbook of political trust, ed. Tom van der Meer, and Sonja Zmerli. Cheltenham: Edward Elgar Publishing.

Victora, C.G., S.R. Huttly, S.C. Fuchs, and M.T. Olinto. 1997. The role of conceptual frameworks in epidemiological analysis: a hierarchical approach. International Journal of Epidemiology 26 (1): 224-227.

Victora, C.G., L. Adair, C. Fall, P.C. Hallal, R. Martorell, L. Richter, and H.P.S. Sachdev. 2008. Maternal and child undernutrition: consequences for adult health and human Capital. Lancet 371:340-357.

WHO. 1995. Physical status: the use and interpretation of anthropometry: report of a WHO Expert Committee. Geneva: WHO. WHO. 2006. WHO child growth standards: length/height-for-age, weight-for-age, weight-for-length, weight-for height and body mass index-for-age: methods and development. Geneva: WHO.

WFP. 2012. The state of food security and nutrition in Yemen. Comprehensive food security survey. WFP: Rome.

\section{Submit your manuscript to a SpringerOpen ${ }^{\circ}$ journal and benefit from:}

- Convenient online submission

- Rigorous peer review

- Immediate publication on acceptance

- Open access: articles freely available online

- High visibility within the field

- Retaining the copyright to your article

Submit your next manuscript at $\boldsymbol{\nabla}$ springeropen.com 